\title{
Incentivos fiscais brasileiros na cadeia de fixadores de energia eólica
}

\author{
Bruno Inácio da Maia ${ }^{1}$ e André Hideto Futami²
}

1 Mestrando em Engenharia de Produção no Centro Universitário da Sociedade Educacional de Santa Catarina (UNISOCIESC) e Graduado em Bacharelado em Engenharia Mecânica pela Faculdade Pitágoras (2013). Gerente de Novos Negócios na Metalúrgica FEY, Brasil. E-mail: inaciodamaia@gmail.com

2 Doutorado em Engenharia de Produto e Processos no PPGEP/UFSC, Mestrado em Engenharia de Produção e Sistemas pela Universidade Federal de Santa Catarina, Especialização em Administração pela Universidade Federal do Paraná e Graduação em Engenharia de Produção (Mecânica) pela Escola Politécnica da Universidade de São Paulo. Docente do Mestrado em Engenharia de Produção do Centro Universitário da Sociedade Educacional de Santa Catarina (UNISOCIESC), Brasil. E-mail: a.futami@gmail.com

RESUMO: Este artigo tem como propósito transparecer o entendimento das montadoras e sua cadeia de fornecimento sobre os incentivos fiscais de compra e venda de fixadores aplicados em aerogeradores para geração de energia eólica no Brasil; de posse deste estudo pode-se comprovar a pífia legislação fiscal aplicada e monitorada nacionalmente em meio às montadoras e a cadeia de fornecimento de fixadores, cabendo, a cada um, entendimentos diferentes, ocasionando desta maneira condições competitivas distintas.

Palavras-chave: Competitividade; Eólico; Fixadores.

Tax incentives in the Brazilian Fasteners for Wind Power

ABSTRACT: This article aims to disclose the understanding of automakers and their supply chain on tax incentives for the purchase and sale of fasteners applied in aerogenerators for wind power generation in Brazil , in possession of this study can prove lackluster applied tax law and monitored nationally among automakers and the supply chain of fasteners, with each a different understanding in this way causing distinct competitive conditions.

Keywords: Competitiviness; Wind Power; Fasteners.

\section{INTRODUÇÃO}

O Brasil é considerado um dos principais países com potencial de geração de energia eólica, conhecida também como energia limpa. A localização geográfica do país proporciona condições atípicas positivas quando comparado com outros países, principalmente em relação à qualidade dos ventos (AMARANTE; BROWER; ZACK, 2001; ABEEOLICA, 2015).

O crescente consumo nacional de energia elétrica aliada à deficiência em fontes de suprimentos de geração de energia elétrica alternativa, além de acordos mundiais para redução de $\mathrm{CO}_{2}$ e desenvolvimento de energias limpas e renováveis, direcionou o desenvolvimento do mercado eólico nacional, formando assim um novo segmento de mercado. Este novo segmento têm como objetivo principal atender as demandas nacionais de incremento de energia e atender aos objetivos ambientais em vigor com as metas de redução de $\mathrm{CO}_{2}$.

No mercado eólico está previsto ocorrer até 2023 um índice de geração de energia 
elétrica derivado de fonte eólica superior a $11 \%$ da matriz energética total, o que respectivamente corresponderá a mais de 22 GW (EPE, 2015; ABEEOLICA, 2015).

Diante deste cenário, frequentemente ocorrem os leilões de energia promovidos pelo Governo, os quais podem trazer benefícios à população e a comunidade onde serão instalados os parques eólicos, como: redução do consumo de combustíveis fósseis, não emissão de gases poluentes e de resíduos sólidos, geração de empregos, desenvolvimento tecnológico e oportunidade de desenvolvimento local.

Para a geração da energia eólica, se faz necessária a manufatura dos aerogeradores e seus componentes. O processo de geração da energia elétrica a partir de fonte eólica é fomentado por intermédio do sol, visto que o vento é uma forma de energia resultante do aquecimento desuniforme da atmosfera pelo sol, das irregularidades da superfície da terra e a rotação do globo terrestre. Os aerogeradores transformam a energia cinética do vento em energia mecânica, a qual é convertida por um gerador em energia elétrica. Para criar a eletricidade, uma turbina trabalha em sentido contrário de um ventilador. $\mathrm{O}$ vento gira as pás que estão acopladas à Nacele (considerado como um compartimento ins-talado no alto da torre dos aerogeradores eólicos, que abriga todos os componentes fundamentais para a produção de energia - como o gerador, a caixa de velocidades e o sistema de transmissão), que por sua vez giram um eixo o qual é instalado a um gerador, produzindo eletricidade. Essa carga elétrica gerada é direcionada para uma estação de armazenamento, que funciona como um grande reservatório e então distribuída pela rede elétrica à população (ABEEOLICA, 2015).

\section{CENÁRIO EÓLICO NO BRASIL}

A fonte de energia limpa derivada dos ventos é conhecida há muitos anos. Incidem registros que na Pérsia, por volta de 200 A.C ocorria a utilização deste tipo de energia para substituição de trabalhos braçais. Encontra-se na Europa, Ásia e algumas localidades no Brasil, parques eólicos para a geração de energia elétrica (AMARANTE; BROWER; ZACK, 2001; OCÁCIA, 2002).

No Brasil, assim como aconteceu na Europa e Ásia, há o processo de industrialização e construção das usinas eólicas. $\mathrm{Na}$ Figura 01 , pode-se avaliar o ranking mundial em capacidade de geração de energia elétrica movida pelos ventos. No ano de 2014, o Brasil foi o $4^{\circ}$ maior instalador mundial de energia eólica com um acréscimo de 2,5 GW e encontra-se na $10^{\circ}$ colocação mundial, um avanço considerável se comparado com a $15^{\circ}$ posição em 2012 e $13^{\circ}$ posição em 2013. A tendência é estar entre os 05 principais países com capacidade instalada até 2023 (GWEC, 2015; ABEEOLICA, 2015).

Figura 01 - Ranking Mundial 2014 da capacidade de geração de energia eólica em (GW).

Figure 01 - World Ranking 2014 capacity of wind power generation (GW).

\begin{tabular}{|c|c|c|c|}
\hline 1 & DE & Chins & 114,78 \\
\hline 2 & 프 & EUA & 65,88 \\
\hline 3 & $=$ & Alemanha & 39,16 \\
\hline 4 & 프 & Espenha & 22.9 \\
\hline 5 & $=$ & India & 2.4 \\
\hline 6 & 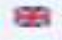 & Reino Unido & 12.4 \\
\hline 7 & $1+1$ & Canada & 9,69 \\
\hline 8 & 11 & França & 9.28 \\
\hline 9 & 11 & Italia & 8,66 \\
\hline 10 & (a) & Brasil & 5,9 \\
\hline
\end{tabular}

\begin{tabular}{|c|c|c|}
\hline 11 部 & Subcia & 5,42 \\
\hline $12 \mathrm{CH}$ & Portugal & 4,91 \\
\hline $13:=$ & Dinamarca & 4,84 \\
\hline 14 . & Polbnis & 3,85 \\
\hline 15 ह & Australia & 3,81 \\
\hline 16 도 & Turquia & 3,76 \\
\hline $17 \mathbf{I I}$ & Roménia & 2,95 \\
\hline $18=$ & Holanda & 2.80 \\
\hline $19 \bullet$ & Japß̊̊ & 2,79 \\
\hline $20 \mathrm{l} \cdot \mathrm{I}$ & México & 2,38 \\
\hline
\end{tabular}

Fonte: ABEEOLICA (2015) 


\section{AEROGERADORES}

O Brasil dispõe de 8 diferentes fabricantes de aerogeradores que concorrem pela demanda: ALSTOM (comprada pela GE), GE, GAMESA, ACCIONA, WEG, VESTAS, WOBBEN e SIEMENS (ABDI, 2014). Diante da relação dos fabricantes, a WEG é a única empresa nacional com projetos norte-americanos tropicalizados; as demais são de origens espanhola e norte-americana.

As empresas de venda de aerogeradores, no Brasil, trouxeram com elas a relação de produtos e demandas de suprimentos que já havia em outros países. Naturalmente, a importação destes insumos é tratada como uma das estratégias de suprimentos, visto que já possuíam os fornecedores homologados e os conheciam antes de aportar no Brasil.

Em contrapartida, o Banco Nacional de Desenvolvimento Econômico e Social (BN$D E S)$ sanciona alguns pré-requisitos para os fabricantes poderem aderir ao programa de financiamento do governo brasileiro. Um dos pré-requisitos é a adesão ao conteúdo nacional com o desenvolvimento de fornecedores locais e compra dos insumos destes fabricantes. O prazo para a finalização do programa de conteúdo nacional esta datado, pelo BNDES, para 01/01/2016, com o mínimo de $70 \%$ do conteúdo nacional (ABEEOLICA, 2015).

Apesar de as demandas para geração de energia advinda dos ventos estarem em fase de ascensão, o fornecimento da cadeia de insumos de aerogeradores ainda não está consolidado no território nacional e, por conta disso, novas estratégias de suprimentos são desenhadas e formuladas diariamente. Os fornecedores homologados estão sob a avaliação diária dos serviços prestados. Novos fornecedores são abordados mediante as necessidades dos fabricantes em aumentar as demandas existentes, dividir a participação das demandas atuais entre os fornecedores, credenciar novas fontes de fornecimento ou mesmo otimizar os custos atuais dos produtos comprados. De acordo com as novas tecnologias e métodos diferenciados para a obtenção do mesmo produto com maior competitividade, isto se torna possível.

\subsection{Estrutura do aerogerador e fixadores}

Conforme ABDI (2014), um aerogerador é compostos por 07 grandes elementos, sendo eles: pás, cubo, eixo, caixa, gerador, nacele e torre.

A estrutura geral dos elementos que compõem os aerogeradores pode ser mais bem entendida conforme segue a Figura 02.

Figura 02 - Componentes básicos de aerogeradores de eixo horizontal (em diferentes configurações).

Figure 02 - Basic components of horizontal axis wind turbines (in different configurations ).
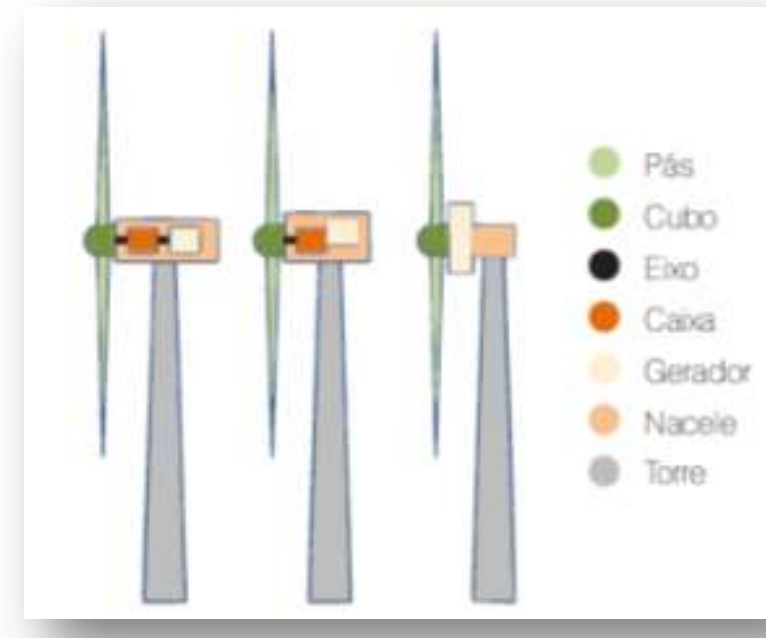

Fonte: $\underline{A B D I}(2014)$

A estrutura de um aerogerador demanda uma diversificada gama de fixadores. Entendem-se como fixadores: parafusos, por- 
cas, arruelas, prisioneiros, hastes roscadas e rebites. Suas aplicações vão desde os subcomponentes que compõem os elementos e equipamentos internos e subconjuntos da nacele, até aos componentes finais, como: chumbamento da base das torres, fixadores estruturais aplicados nas flanges das torres, fixadores das pás quais são acoplados à nacele e os fixadores estruturais da nacele.

A montagem dos aerogeradores nos parques eólicos é composta dentre outros insumos, por fixadores. A seguir, evidencia-se separadamente por componentes, como é feita a aplicação dos fixadores na montagem dos elementos que compõe os aerogeradores.

A utilização dos elementos de fixação é atribuída desde a fundação das torres. A fixação da base da torre tem o objetivo principal de deixar a torre estática, é a partir de onde serão montados os demais segmentos da torre, e os demais componentes que compõem o aerogerador. Conforme segue a Figura 03, pode-se entender melhor onde são aplicados estes fixadores na base das torres eólicas.

Figura 03 - Aplicação de Fixadores nas bases das torres eólicas. Figure 03 - Fastener application on the basis of wind towers.

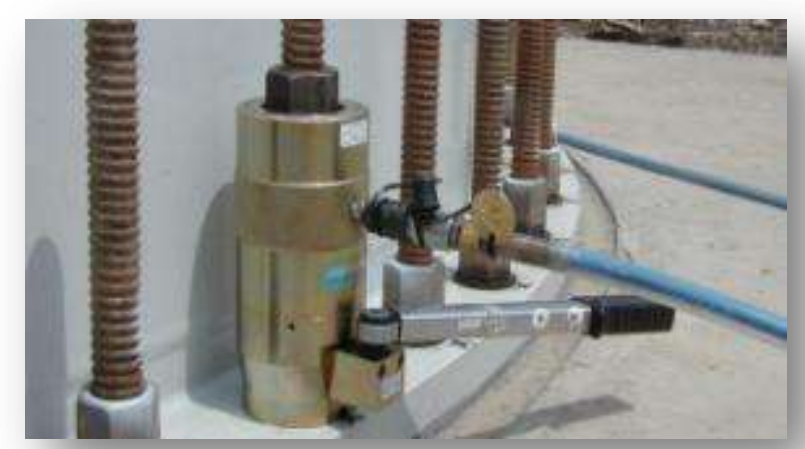

Fonte: $\underline{A B D I}(2014)$

De uma forma sequencial, após a fixação da fundação da torre são acoplados os demais segmentos que compõem a torre, a união entre um segmento da torre e o outro é composta por fixadores (parafusos, porcas e arruelas) que são montados nas flanges entre um segmento e outro. Conforme ilustrado na Figura 04, pode-se entender melhor como é feito esta montagem entre um segmento e outro pelas flanges.

Figura 04 - Aplicação de Fixadores nas torres eólicas.

Figure 04 - Fastener application on the wind towers .

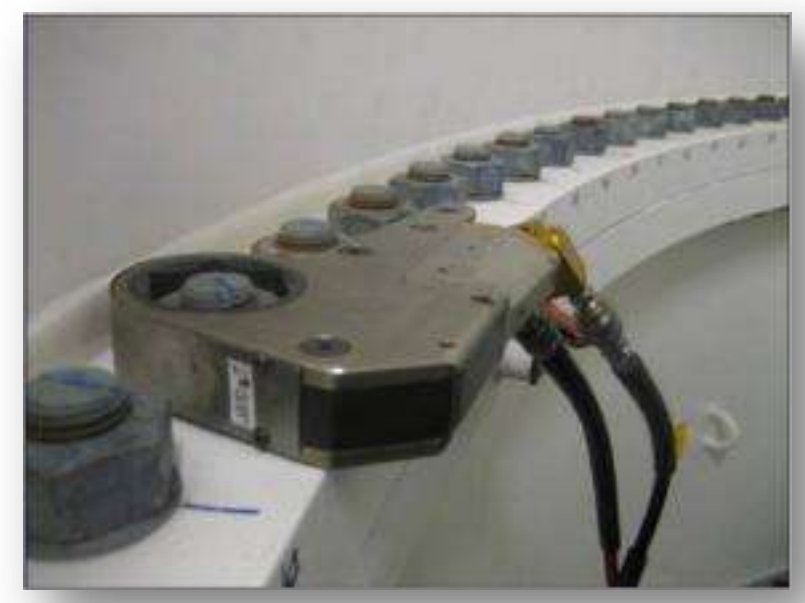

Fonte: $\underline{A B D I(2014)}$

Após a montagem da torres, os componentes de fixação são aplicados na montagem do rotor com a nacele. A Figura 05 ilustra onde são aplicados estes fixadores.

Figura 05 - Aplicação de Fixadores no rotor e nacele. Figure 05 - Fastener application in rotor and nacelle.

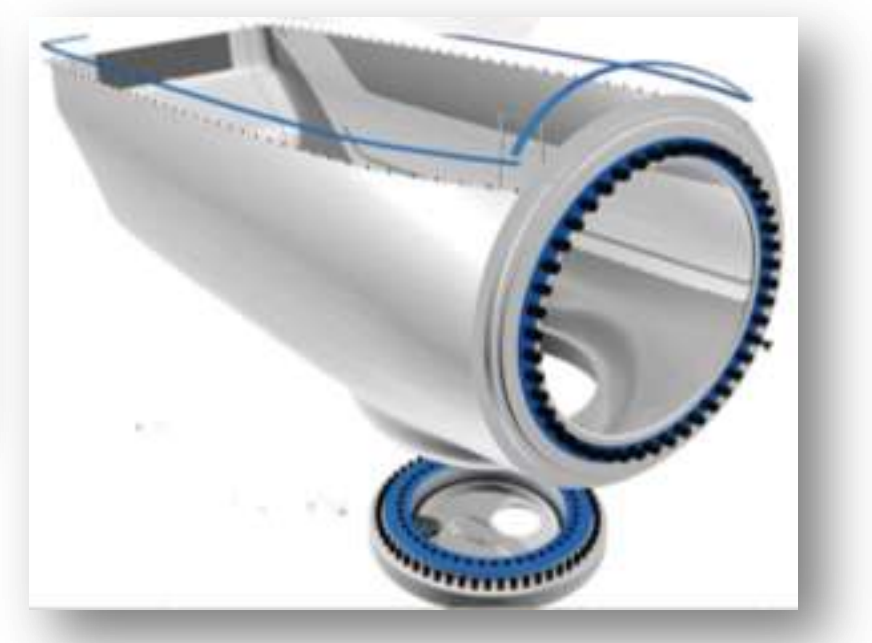

Fonte: $\underline{A B D I}(2014)$ 
São aplicados fixadores nas pás dos aerogerados, as quais são acopladas no rotor. Conforme ilustrado na Figura 06 , pode-se ter um melhor entendimento.

Figura 06 - Aplicação de Fixadores nás pás dos erogera-dores. Figure 06 - Fastener application in blade in wind turbine.

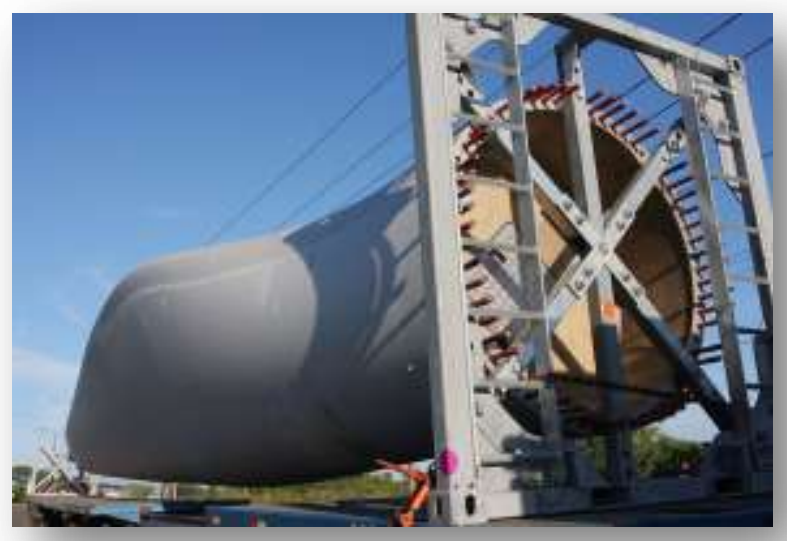

Fonte: $\underline{A B D I}(2014)$

Os fixadores são inerentes aos elementos de fixação e foram apresentados nas aplicações acima. Considerados como produtos estruturais, podendo variar as suas dimensões, classes de resistência, especificações e tratamentos superficiais de acordo com a necessidade de cada fabricante de aerogerador.

Conforme informado pela Agência Brasileira de Desenvolvimento Industrial (ABDI) no mapeamento da cadeia produtiva da indústria eólica brasileira, existe o mapeamento de 04 fornecedores nacionais homologados de fixadores ao mercado brasileiro. Contudo, as demandas do mercado oscilam ao longo dos anos, conforme os leilões governamentais são efetivados, assim como a participação de cada fabricante em relação ao potencial deste mercado (ABDI, 2014).

Cada um dos fabricantes de aerogeradores detém uma determinada fatia do mercado de geração de energia eólica. A procura destas empresas por fontes de forneci- mento com diferenciais competitivos aos mapeados inicialmente é uma constante, conforme colocado pela ABDI (2014). A competição do mercado de energia eólica existe entre os fabricantes de aerogeradores e os fabricantes de insumos e componentes a estes fabricantes, que competem todos entre si. As competências de cada fabricante é o diferencial que determina quem está apto a fornecer e lucrar com o mercado de energia eólica (PORTER, 1989; ABDI, 2014).

\subsection{Incentivos fiscais para fabricação de aerogeradores}

Algumas empresas fabricantes de aerogeradores entendem e aplicam a alíquota zero do IPI (Impostos sobre Produtos Industrializados) e das contribuições sociais PIS/COFINS (Programas de Integração Social/Contribuição para Financiamento da Seguridade Social), assim como a isenção do ICMS (Imposto sobre Circulação de Mercadorias e Serviços), com a justificativa que os produtos adquiridos de seus fornecedores se destinam única e exclusivamente à industrialização de componentes, classificados na posição NCM no 8503.00.90, a serem empregados na produção de aerogerador (NCM no 8502.31.00), com aplicação de alíquota zero e isenção para os seguintes tributos:

a) IPI - Decreto $n^{\circ} 6.890$, de 29 de junho de 2009, através do seu artigo $2^{\circ}$, alterou a TIPI (Tabela de Incidência do Imposto sobre Produtos Industrializados) na vigência do Decreto n ${ }^{\circ} 6.006 / 2006$, ao incluir o "EX" tarifário na posição 85.03 .00 .90 , para atribuir alíquota zero do IPI para os componentes agregados ao aerogerador (NCM $\mathrm{n}^{\circ}$ $8502.31 .00)$, sendo mantida tal alíquota na 
vigente da TIPI (Decreto $n^{\circ}$ 7.660/2011), conforme (BRASIL, 2009);

NCM: 8503.00 .90

Descrição: Partes utilizadas exclusivamente ou principalmente em aerogeradores classificados no código $\mathrm{NCM}$ n $^{\circ} 8502.31 .00$ e Alíquota (\%): $0 \%$

b) PIS/COSINS - Lei $n^{\circ} 10.865$, de 30 de abril de 2004, o qual teve seu artigo $n^{\circ} 28$ alterado, pela Lei $\mathrm{n}^{\circ} 13.097$, de 19 de janeiro de 2015, para incluir o inciso XXXVII, prevendo a redução da alíquota zero para o PIS/COFINS incidentes sobre a receita bruta decorrente dos produtos classificados no "Ex" tarifário 01 do código NCM $n^{\circ} 8503.00 .90$ da TIPI acima citada;

c) ICMS - Convênio ICMS n¹01, de 18 de dezembro de 1997, em sua Cláusula Primeira, inciso $\mathrm{VIII}, \S 1^{\circ}, \S 2^{\circ}, \S 3^{\circ}$, com suas posteriores alterações ocorridas até o Convênio ICMS n 10/2014, foi concedida a isenção do ICMS às operações com os produtos aerogerador de energia eólica (BRASIL, 1997).

Desta forma, é orientado por estas empresas que as remessas de produtos deverão ser expedidas com a aplicação de alíquota zero de IPI e PIS/COFINS e isenção do ICMS, sendo que no corpo da Nota Fiscal relativa a essas mercadorias deverão constar as expressões "Saída com alíquota zero de IPI e PIS/COFINS" e "Saída com isenção de ICMS", respectivamente com a indicação da legislação acima citada.

Na NCM de incentivos fiscais em relação aos fabricantes de componentes destinados aos aerogeradores não há menção direta sobre os elementos de fixação, deixando, assim, duvidosos o seu entendimento. Em contrapartida, para os fixadores existem legislações próprias.
De acordo com a legislação do Decreto no 7.212, de 15 de junho de 2010 que regulamenta a cobrança, fiscalização, arrecadação e administração do IPI, e o decreto no 8.544 , de 21 de outubro de 2015, que altera o Decreto no 7.819 , de 03 de outubro de 2012, que regulamenta os artigos 40 à 44 da Lei no 12.715 , de 17 de setembro de 2012, que dispõe sobre o Programa de Incentivo à Inovação Tecnológica e Adensamento da Cadeia Produtiva de Veículos Automotores - Inovar-Auto e o Decreto no 7.660, de 23 de dezembro de 2011, que aprova a Tabela de Incidência do Imposto sobre Produtos Industrializados - TIPI. , na NCM para elementos de fixação deverão ser considerados o grupo NCM 7318 e, portanto, não poderiam ser classificados como "partes e peças para aerogeradores", o que impacta na tributação normal do PIS/COFINS, IPI e ICMS conforme alíquotas abaixo:

- ICMS: $12 \%, 17 \%$ ou $7 \%$ (conforme Estado de destino);

- IPI: $10 \%$ - conforme tabela TIPI NCM 7318

- PIS/COFINS: Alíquota 9,25\% regime tributação não cumulativo.

Conforme exposto acima, existem interpretações distintas para o mesmo assunto. O qual uma holística beneficia a cadeia de aerogeradores isentando os impostos dos fixadores que são destinados a este segmento, todavia, o outro entendimento aponta para a tributação dos impostos dos mesmos fixadores.

A legislação que trata da isenção dos impostos não traz a listagem de NCM dos componentes e insumos que aderem a este beneficio, é tratado de forma macro. Deixando assim lacunas de dúvida se os fixado- 
res participam ou não da isenção de impostos.

\section{METODOLOGIA DE PESQUISA}

Conforme exposto, a dissonância e falta de clareza em relação aos incentivos fiscais, se torna imperativa a dúvida se a mesma NCM utilizada para os incentivos fiscais em relação aos elementos que compõem os aerogeradores é aplicada aos fixadores, que também o compõem. Devido a isto, foi estruturada uma pesquisa de campo com os fabricantes de aerogeradores para averiguar se os mesmos compram os fixadores nacionalmente com ou sem o incentivo de impostos.

As perguntas foram formatadas de forma objetiva em questões diretas com as opções de respostas (sim ou não). O público a que foram endereçadas as perguntas eram os responsáveis pela parte de suprimentos de cada fabricante de aerogerador, que deveriam responder com o que pratica atualmente amparado respectivamente pelas diretivas fiscais-contábeis de entendimento cada organização.

A referida pesquisa fora feita presencialmente com as pessoas responsáveis pelas compras dos fixadores, com a aplicação de um questionário de 03 perguntas.

O objetivo geral do questionário é de evidenciar a posição de cada organização no quesito que se deve ser aplicado à isenção de impostos aos fixadores ou não. As perguntas feitas seguem conforme abaixo.

10 A empresa entende que os fixadores (parafusos, porcas, arruelas, prisioneiros, hastes roscadas e rebites) devem ser fornecidos com a isenção de impostos?

$2^{\circ}$ A empresa têm entendimento da legislação fisco-contábil brasileira? $3^{\circ}$ A empresa possui fornecedores que fornecem os produtos com o mesmo entendimento (ou seja, com a isenção de impostos)?

O público pesquisado foram as 8 organizações que compõem o portfólio de fabricantes de aerogeradores com operações nacionais, sendo elas: ALSTOM (Comprada pela GE), GE, GAMESA, ACCIONA, WEG, VESTAS, WOBBEN e SIEMENS. Obteve-se o retorno de $100 \%$ das empresas pesquisadas.

\section{RESULTADOS DA PESQUISA}

De acordo com as respostas recebidas de cada organização, pode-se avaliar como o mercado pratica a questão fiscal-contábil e o entendimento de cada fabricante em relação aos incentivos.

As organizações não foram nominadas individualizadamente de modo a privar a sua identidade e não revelar a estratégia adotada para compra de fixadores. Portanto, serão identificadas com letras do alfabeto de modo aleatório em relação à posição inicial descrita neste artigo.

Conforme pode ser avaliado na Tabela 1 , $63 \%$ das organizações aderem ao programa de incentivo fiscal utilizando para a compra de fixadores e $37 \%$ das organizações não aderem para este fim. As respostas dos $37 \%$ que não aderem ao incentivo fiscal estendendo para compra de fixadores é principalmente porque existe uma NCM própria para a compra dos fixadores, não sendo válida fiscalmente a utilização da NCM de incentivos para a compra de elementos de aerogeradores, suplementarmente informaram que fazem uso da NCM de incentivo para determinados elementos que com- 
põem o aerogerador, porém, não contempla os fixadores.

Tabela 1 - Aderência ao Incentivo de compra de fixadores sem impostos

Table 1 - Taxes without fasteners purchase adherence to Incentive

\begin{tabular}{c|c|c|c}
\hline \multicolumn{2}{c|}{ ORGANIZAÇÃO } & SIM & NÃO \\
\hline 1 & $\mathrm{~A}$ & $\mathrm{X}$ & \\
\hline 2 & $\mathrm{~B}$ & & $\mathrm{X}$ \\
\hline 3 & $\mathrm{C}$ & $\mathrm{X}$ & \\
\hline 4 & $\mathrm{D}$ & $\mathrm{X}$ & \\
\hline 5 & $\mathrm{E}$ & & $\mathrm{X}$ \\
\hline 6 & $\mathrm{~F}$ & $\mathrm{X}$ & \\
\hline 7 & $\mathrm{G}$ & & $\mathrm{X}$ \\
\hline 8 & $\mathrm{H}$ & $\mathrm{X}$ & \\
\hline \multicolumn{4}{c|}{ TOTAL } \\
\hline \multicolumn{2}{|c|}{$\%$} & $63 \%$ & $37 \%$ \\
\hline
\end{tabular}

Fonte: Pesquisa de campo

Em contrapartida os $63 \%$ das organizações que aderem a esta política de incentivos, alegam que os elementos de fixação utilizados nas estruturas estão contidos indiretamente na NCM de incentivos fiscais que as isentam dos impostos.

Competitivamente existe um impacto direto entre os fornecedores atuais e os potenciais de fixadores, visto que o entendimento e aplicação das políticas adotadas pelas organizações que são fabricantes de aerogeradores são estendidos para toda cadeia. Se a organização optar por aderir e estender o entendimento em receber os fixadores sem impostos, fará inferência ao fornecedor para aplicar a mesma política.

Os impactos econômicos aos fornecedores correspondem diretamente na redução de custos e maior competitividade em virtude da aplicação e aceite da NCM de incentivo. O preço de venda é um forte fator determinante para desenvolvimento de uma fonte de fornecimento, se houver atendimento a todos os outros requisitos que o cliente julgar como importante (HAMEL; PRAHALAD, 1995).
Em contrapartida se o fornecedor aderir ao programa de incentivos e a Receita Federal do Brasil (RFB) entender que o NCM de produtos de fixação não pode ser considerado como "partes e peças para aerogeradores", este fornecedor será autuado e pagará multa para a Receita Federal (CASSONE, 2010).

Identificada à divergência de NCM, a RFB lavrará auto de infração e aplicará multa de ofício, acrescido de juros, conforme entendimento do Conselho Administrativo de Recursos Fiscais da RFB. Podem ser exigidas notas fiscais emitidas até 05 anos anteriores à fiscalização

O Artigo 44, inciso I da Lei no 9.430/1996 estabelece multa no percentual de $75 \%$ sobre a totalidade ou diferença do imposto ou contribuição nos caso de falta de pagamento ou recolhimento, falta de declaração e nos casos de declaração inexata. Tal percentual, de acordo com o $\S 1$ 음 do mencionado artigo, poderá ser duplicado caso a prática seja interpretada como sonegação, fraude ou conluio, sem prejuízos de outras penalidades administrativas ou criminais cabíveis.

\section{CONSIDERAÇÕES FINAIS}

O Brasil vive um momento de transformação em sua base energética, tornando-se necessário, para atendimento às demandas de consumo futura, e atendimento às políticas internacionais de energias limpas e redução de emissão de $\mathrm{CO}_{2}$.

Conforme o mapeamento realizado pela ABDI o Brasil passa pela criação do parque nacional de fornecedores ao segmento eólico. Um dos fatores principais é o programa de conteúdo nacional, qual implica que para 
a aprovação de financiamentos pelo BNDES a fabricante de aerogerador compre no mínimo $70 \%$ dos insumos produzidos no território nacional.

A política fiscal causa dúvidas em relação como deve ser aplicada e como todos podem se beneficiar dos incentivos sem o receio de serem autuados ou discordar das regras nacionais de comercialização.

Fica evidente a possibilidade de interpretação dúbia entre as legislações, pois a atuação de todos os fornecedores e fabricantes deve ser única, não deixando margens para dúvidas e arbitramento conforme entendimentos únicos, o que impacta diretamente no recolhimento ou não de impostos.

O impacto duvidoso da aplicação do incentivo fiscal na cadeia de fornecedores de fixadores é prejudicial para a competitividade das organizações. Estas destoam as reais competências dos fornecedores e as camuflam por furos na política fiscal nacional.

Por fim, aconselha-se às organizações que atuam com vendas de fixadores para o segmento eólico que façam consultas formais à Receita Federal. Importante frisar que a consulta realizada por uma organização, mesmo que seja sobre o mesmo assunto, vale apenas á organização que registrou á consulta, não podendo ser utiliza e replicada pelas demais, ou seja, cada empresa precisa entrar com seu pedido de consulta.

\section{REFERÊNCIAS}

ABDI. Mapeamento da cadeia produtiva da indústria eólica no Brasil. Brasília: ABDI ANPROTEC, 2014. p. 1-152.

AMARANTE, O. A. C.; BROWER, M.; ZACK, J. Atlas do Potencial Eólico Brasileiro. MME/ Eletrobrás/CEPEL, Brasília, p. 01-45, 2001.
ATLAS DO POTENCIAL EÓLICO BRASILEIRO. Centro de Pesquisas de Energia Elétrica CEPEL. Brasília, 2001 ASSOCIAÇÃO BRASILEIRA DE ENERGIA EÓLICA. Boletim de Dados julho/2015, 2015 Disponível em: <http://abeeolica.org.br/pdf /Boletim-de-Dados-ABEEolica-Julho-2015Publico.pdf>. Acesso em 17 out. 2015. BRASIL. Decreto no 6.890, de 2009. Altera a Tabela de Incidência do Imposto sobre Produtos Industrializados - TIPI, aprovada pelo Decreto no 6.006, de 28 de dezembro de 2006. Diário Oficial da União, Brasília, DF, junho 2009.

BRASIL. Decreto 6.006, de 28 de dezembro de 2006. Aprova a Tabela de Incidência do Imposto sobre Produtos Industrializados TIPI. Diário Oficial da União, Brasília, 29 dez. 2006.

BRASIL. Protocolo ICMS no 198 de 2009. Disponível em: <http://www.fazenda.gov. br/confaz>. Acesso em: 27 out. 2015.

BRASIL. Convênio ICMS 101/97, de 12 de dezembro de 1997. Concede isenção do ICMS nas operações com equipamentos e componentes para o aproveitamento das energias solar e eólica que especifica. Disponível em: <http://app1.sefaz.mt.gov.br/ sistema/legislacao/legislacaotribut.nsf/07fa 81bed2760c6b84256710004d3940/f219de0 bc8dbf2ce832567940040cc22?OpenDocum ent>. Acesso em: 13 out. 2015.

CASSONE, V. Direito tributário: fundamentos constitucionais da tributação, definição de tributos e suas espécies, conceito e classificação dos impostos, doutrina, prática e jurisprudência. 21. ed. São Paulo: Atlas, 2010.

EPE - Empresa de Pesquisa Energética. Balanço Energético Nacional 2015: Ano Base 2014. Rio de Janeiro, RJ, Brasil. 
GWEC - GLOBAL WIND ENERGY COUNCIL. Global Wind Report - Annual Market Update 2014, Bruxelas, Bélgica, mar. 2015. HAMEL, G.; PRAHALAD, C. K. Competindo pelo Futuro: estratégias inovadoras para obter o controle do seu setor e criar os mercados de amanhã. Rio de Janeiro: Campus: 1995.

OCÁCIA, G. C. Energia Eólica - Estado da Arte e Algumas Projeções. Revista do Centro de Tecnologia da Ulbra, Rio Grande do Sul, ULBRA, v. 3, n. 2, 2002.

PORTER, Michael E. A vantagem competitiva das nações. Rio de Janeiro: Campus, 1989.

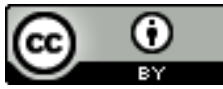

License information: This is an openaccess article distributed under the terms of the Creative Commons Attribution License, which permits unrestricted use, distribution, and reproduction in any medium, provided the original work is properly cited.

Artigo recebido em 29 de novembro de 2015.

Avaliado em 10 de março de 2016.

Aceito em 13 de abril de 2016.

Publicado em 25 de maio de 2016.

Como citar este artigo (ABNT):

MAIA, Bruno Inácio da; FUTAMI, André Hideto. Incentivos fiscais brasileiros na cadeia de fixadores de energia eólica. Estação Científica (UNIFAP), Macapá, v. 6, n. 1, p. 4352, jan./abr. 2016. 